\title{
Atlas lingüístico pluridimensional del español en Belice \\ (ALEB) \\ Nivel fonético
}

Mauricio Andrés Cardona Ramírez

Universidad de Bergen

\section{Introducción}

El presente artículo tiene como finalidad dar a conocer parte del resultado logrado a partir del esfuerzo colectivo que tiene como propósito la consecución del Atlas Lingüístico de América Central (ALAC), dirigido por Miguel Ángel Quesada Pacheco. ${ }^{1}$ Nuestro aporte a dicho atlas incluye la ilustración cartográfica de la articulación de 61 contextos fonéticos, los cuales tienen como fin dar una idea sintetizada del estado de la pronunciación del español en Belice desde un punto de vista articulatorio. Para ello, el presente artículo ofrece una colección de 61 mapas lingüísticos pluridimensionales que permiten distinguir los resultados según la edad y el sexo de los informantes. Cabe también mencionar que el presente atlas es el fruto del trabajo realizado para mi proyecto doctoral inscrito en la Universidad de Bergen, Noruega, y que está pronto a su culminación.

Así, bajo una visión pluridimensional aplicada a la metodología de la geografía lingüística tradicional, la ilustración de estos contextos fonéticos en el plano cartográfico favorece la ampliación del panorama lingüístico de la lengua española en el territorio centroamericano. No obstante, cabe aclarar que a pesar de incluir variables sociales como parte del aspecto pluridimensional de este trabajo, este está lejos de considerarse dentro de la rama de la sociolingüística. Más bien, se considera parte de una tradición dialectológica modernizada y basada en los principios de la geografía lingüística.

Nuestro trabajo, entonces, amplía de manera considerable lo que hasta ahora se conoce de la articulación fonética del español en Belice. Tradicionalmente, este país ha recibido poco interés académico en cuanto a la descripción del español que allí se

\footnotetext{
1 http://www.uib.no/fremmedsprak/forskning/forskingsprosjekt-ved-if/spraakvariasjon-imellom-amerika.
} 
habla. Es por ello que, además, esta ilustración cartográfica representa la validación y el reconocimiento de una variante dialectal del español en evolución, que se gesta en este territorio. Aunque aún se encuentra en estado embrionario, esta variante ya parece presentar señales de autenticidad e identidad propia beliceña. De allí que bien podríamos pronosticar que, en un futuro no muy lejano, nos referiremos a esta variante como el español beliceño y no simplemente como el español en Belice. Pero ese futuro aún no ha llegado y, por ello, aquí nos referimos a esta como el español en Belice.

\section{Contexto lingüístico de Belice}

Belice es el país más pequeño de América Central con apenas $22.966 \mathrm{~km}^{2}$ y 312.698 habitantes (según el censo de 2010). Sin embargo, esto no lo hace un país poco interesante lingüísticamente. La configuración actual de la interacción lingüística beliceña es el resultado de una historia convulsionada, de constantes cambios y reconfiguraciones demográficas. Cada reconfiguración demográfica implica una reconfiguración lingüística, y es justo el intenso ritmo cambiante que mantiene esta nación a nivel etnográfico y cultural lo que ha dejado una imprenta de identidad basada, precisamente, en esa característica multiétnica y multicultural.

Solo podemos hablar de una etnia realmente autóctona de la región, por haber hecho presencia en esta por más de 3000 años: los mayas (Shoman 1994, 3). Este grupo representa, sin duda alguna, el vínculo genealógico más antiguo con los ancestros que alguna vez representaron la civilización más avanzada y extendida de este territorio. No obstante, a lo largo de la historia, las comunidades mayas en la región han sido diezmadas de manera significativa. En la actualidad representan solo el $10 \%$ del total de la población beliceña, con poco o ningún impacto en el pensamiento occidental que controla el país política y económicamente.

Por lo tanto, las tres lenguas que se desprenden de estas comunidades en el territorio beliceño (maya quekchí, maya mopán y maya yucateco) se mantienen al margen de la vida política y comercial del país. Las demás lenguas en Belice llegaron a la región a partir de la campaña colonizadora de los españoles y, posteriormente, por el dominio británico del país. De allí que tanto el español (50\%) como el criollo de base inglesa (21\%) son hoy por hoy las lenguas más escuchadas en Belice, según el censo de 2010. Pero también se escucha en Belice el garífuna (5\%), el inglés $(6 \%)$, el 
hindi, el chino (1\%), el bajo alemán (3\%), el holandés y otras. Además, sin ser aún la lengua materna de nadie, sino más bien un pidgin que funciona como lengua franca y que se desarrolla en las calles y en los ambientes más informales, escuchamos en Belice una variedad de spanglish, mezcla del criollo de base inglesa y el español.

Extrañamente, a pesar de que los hablantes de inglés en Belice representan apenas el 6\% del total, es precisamente el inglés la lengua oficial del país. Esta es una situación que ha llevado a que en Belice la gran mayoría de sus habitantes interactúen en dos o más lenguas. Es decir, su lengua nativa (español, garífuna, maya, etc.), la lengua franca (ya sea el criollo beliceño o el spanglish) y el inglés. No obstante, el inglés suele limitarse al entorno académico, turístico, o al contexto meramente oficial.

En cierto sentido, esta realidad lingüística beliceña refleja la realidad administrativa actual de la nación. Si bien Belice proclamó su independencia de la corona inglesa en el año 1981, aún permanece fuertemente ligada a los designios y políticas de la corona inglesa. Las disputas administrativas que no puedan ser solucionadas por los mandatarios beliceños, son resueltas directamente desde el Reino Unido. Su pertenencia a la Commonwealth también impone ciertas condiciones que se reflejan en la lengua, como por ejemplo, que el inglés sea su lengua oficial.

Ahora, en la práctica, Belice es a todas luces un país multiétnico, multicultural y plurilingüe. Las cortas distancias geográficas entre los centros urbanos contrastan con la enorme diversidad etnográfica y cultural que se observa por todo el país. Infortunadamente, la escasez de políticas estatales de protección que procuren la protección de la multiculturalidad, además de la ausencia de su reconocimiento constitucional, dejan sin base jurídica la participación lingüística de las lenguas mayoritarias en el quehacer administrativo y educacional del país. En la tabla 1 se ilustra dicha situación desde el punto vista constitucional, en comparación con otros países centroamericanos.

Como vemos en la tabla 1, en Belice hay poca voluntad política para integrar en un marco político y administrativo estrategias de conservación multicultural. En el caso de las comunidades hispanohablantes beliceñas, dicho aislamiento político ha venido configurando una variante del español nacida de las oleadas de inmigrantes guatemaltecos, salvadoreños, yucatecos y hondureños que han estado llegando al país, sobre todo, a partir de los años 80 . Pero no son los inmigrantes propiamente los 
artífices de la nueva variante beliceña, sino los jóvenes resultado de generaciones posteriores.

Tabla 1. La multiculturalidad reflejada en algunas de las constituciones centroamericanas

\begin{tabular}{|c|c|c|c|c|c|c|}
\hline País & $\begin{array}{l}\text { Carácter } \\
\text { multiétnico }\end{array}$ & $\begin{array}{l}\text { Convenio } \\
169^{2}\end{array}$ & $\begin{array}{l}\text { Educación } \\
\text { Bilingüe }\end{array}$ & $\begin{array}{l}\text { Educación } \\
\text { intercultural }\end{array}$ & Autonomía & $\begin{array}{l}\text { Propiedad } \\
\text { comunitaria }\end{array}$ \\
\hline Belice & No & $\begin{array}{l}\text { No } \\
\text { ratificado }\end{array}$ & No figura & No figura & No figura & No figura \\
\hline Guatemala & $S i$ & Ratificado & $\begin{array}{l}\text { Artículo } \\
76\end{array}$ & No figura & $\begin{array}{l}\text { Respeto a } \\
\text { sus formas } \\
\text { de vida }\end{array}$ & Artículo 67 \\
\hline Panamá & $S i$ & $\begin{array}{l}\text { No } \\
\text { ratificado }\end{array}$ & $\begin{array}{l}\text { Artículo } \\
84\end{array}$ & $\begin{array}{l}\text { Indirectamente. } \\
\text { Art. } 104\end{array}$ & $\begin{array}{l}\text { Comarcas } \\
\text { indigenas. } \\
\text { Artículo } \\
141\end{array}$ & $\begin{array}{l}\text { Artículos } \\
122,1 \text { y 2, } \\
123\end{array}$ \\
\hline Nicaragua & $S i$ & $\begin{array}{l}\text { No } \\
\text { ratificado }\end{array}$ & $\begin{array}{l}\text { Artículo } \\
121\end{array}$ & Artículo 121 & $\begin{array}{l}\text { Artículos } \\
\text { 5, 89, 175, } \\
\text { 177, 181, } \\
\text { 181. Art. } \\
20\end{array}$ & $\begin{array}{l}\text { Artículo 5, } \\
89 . \quad 103, \\
107,180\end{array}$ \\
\hline
\end{tabular}

Fuente: Segundo Informe sobre Desarrollo Humano en Centroamérica y Panamá, capítulo 8.

Para bien o para mal, el español que se habla en Belice entre los jóvenes es un español crecido al libre albedrío. La falta de regulación y enseñanza del español desde la escuela primaria ha conducido a que las variantes familiares y coloquiales se desarrollen en total independencia del canon normativo de las academias de la lengua española. Las formas arcaicas y las innovaciones dialectales, entremezcladas en contextos comunes, son parte de la cotidianidad lingüística del español en Belice.

2 http://www.ilo.org/indigenous/Conventions/no169/lang--es/index.htm 
También el spanglish beliceño, el cual varía según la región del país, tiene un papel importante dentro de la evolución informal del español. Este se fortalece cada vez más entre las nuevas generaciones, lo que confirma la estrecha relación intercultural que, inevitablemente, se adapta de manera natural al nuevo contexto creando sus propias herramientas comunicativas.

Debe anotarse, también, que el español en Belice no goza de mucho prestigio social ni político. La lengua tiene una asociación directa al grupo que la habla, y dado que los grupos inmigrantes en Belice son en su gran mayoría campesinos y gente de bajo estatus económico, procedentes de otras regiones de Centroamérica, el español es percibido como una lengua de poca importancia económica y socio-política. Este es, en nuestra opinión, otro de los factores que acelera el crecimiento del spanglish entre los jóvenes, y el desinterés político de incluir el español como lengua cooficial en el país.

En resumidas cuentas, Belice es un pequeño país con una diversidad étnica y cultural inmensa. Desde el punto de vista lingüístico académico, Belice representa una oportunidad magnífica para el estudio del español en contacto con otras lenguas. El reducido tamaño del país y el grado de interacción intercultural y lingüístico hacen de este país un laboratorio verdaderamente interesante para el entendimiento de la dinámica de las lenguas en contacto.

\section{Estado de la cuestión}

El estudio de la lengua española en Belice ha estado prácticamente ausente entre los académicos de esta lengua. Su mención académica ha estado, tradicionalmente, limitada a la relación o influencia que el español pueda tener en otras lenguas del país (Verbeeck 1999; Escure 2004). Es, posiblemente, la idea de que el español en Belice se limita al español de las regiones que provienen los inmigrantes, lo cual parece desmotivar la realización de estudios más detallados sobre la lengua española en este país.

No obstante, hay un breve informe de la pronunciación del español en Belice en Notas del español de Belice, llevado a cabo por Antonio Quilis en 1999. Dicho aporte surge del Atlas Lingüistico de Hispanoamérica (ALHA), propuesto por Antonio Quilis y Manuel Alvar en 1984. Aunque inicialmente Belice no figuraba en el 
itinerario del ALHA, Antonio Quilis decidió incluirlo a último momento como parte de su recorrido por Centroamérica, siendo este el último país visitado por el dialectólogo para completar el segundo volumen del ALHA.

El informe de las observaciones en Belice logradas por Antonio Quilis provienen de cuatro poblaciones: Benque Viejo del Carmen, San Pedro, Corozal y Ciudad Belice. De ellas, las tres primeras coinciden con parte del grupo de localidades recorridas en nuestro trabajo. En lo que respecta a la fonética, Antonio Quilis dedica dos páginas a la pronunciación, de donde destacamos las siguientes observaciones:

- El seseo y el yeísmo es general en todas las regiones observadas.

- Las oclusivas sonoras se realizan en su mayoría como en el resto de los países hispanohablantes, es decir, con el alófono fricativo tras consonantes sonoras o en posición intervocálica. No obstante, el fonema /b/ se registró con el alófono [v] en el caso de viruela [vir'gwela].

- El fonema /f/ se articula bilabial en Benque Viejo y San Pedro. También puede observarse como glotal aspirado fui [hwi].

- El fonema fricativo palatal [i] se debilita hasta el punto de desaparecer entre vocales, como en amarillo [ama'rio], gallina [ga'ina]. Al inicio de palabra, después de pausa es fricativo, y en la combinación -ny- se da como fricativo o incluso puede sibilarse: inyección [injek'sjon].

- El fonema africado /t $\mathrm{f} /$ es más oclusivo que africado.

- Hay despalatalización del fonema nasal palatal /n/. Caña [kanja].

- Los grupos $/ \mathrm{t} r / \mathrm{y} / \mathrm{d} \mathrm{r} / \mathrm{se}$ mantienen estables.

- Se observaron algunos casos de rotacismo y de lambdacismo.

En resumidas cuentas, podemos decir que Antonio Quilis no observó mayores variaciones de lo que se da en el resto de los países hispanoamericanos. Incluso en los casos de mayor variación, como la glotalización de /f/, el debilitamiento y pérdida de /i/, y la despalatalización de /n/, son también casos que se observan con frecuencia en las zonas rurales de la mayoría de los países hispanohablantes. Teniendo en cuenta que la mayor parte de los grupos inmigrantes hispanohablantes en Belice proviene de poblaciones rurales, no es difícil suponer la presencia de estos fenómenos dialectales en el país. 


\section{Breve marco teórico y metodológico}

Las bases teóricas que sostienen el presente trabajo vienen de una de las metodologías más productivas del siglo XX en materia de investigación dialectal: la geografía lingüística (Montes 1970; Coseriu 1985; Gimeno 1990; Chambers \& Trudgill 1994; García 1996, 77; Milroy \& Gordon 2003, 11-22; Colán 2005; etc.). Dicha metodología está estrechamente relacionada a la dialectología tradicional, pues es allí de donde ha surgido la mayor cantidad de resultados que aplican el método geográfico lingüístico al estudio de la variación lingüística. No es extraño, por lo tanto, que se suela hacer referencia a la geografía lingüística como sinónimo de la dialectología tradicional: "the systematic study of all forms of dialect, but specially regional dialect, is called dialectology, also ‘linguistic geography' or dialect geography” (Crystal 2003, 136).

Pero debemos aclarar que la geografía lingüística es un método con la potencialidad de ser aprovechado por cualquier disciplina que tenga como objetivo la descripción y, eventualmente, la explicación de variantes lingüísticas. En sí, la geografía lingüística no puede ser considerada una ciencia independiente, y se acomoda mejor con el apelativo de método (Iordan 1970, 144; Coseriu 1985, 154). Sus objetivos no van más allá de la facilitación metodológica a otras disciplinas de la lingüística. En sí misma no puede ofrecer generalizaciones o teorizaciones que permitan sentar bases para el entendimiento de la lengua viva. Por lo tanto, adoptar el término 'geografía lingüística' como sinónimo de 'dialectología tradicional' sería un error que queremos evitar aquí.

La 'dialectología tradicional', suele ser percibida como aquella disciplina que basa su argumentación lingüística en la información obtenida de los NORMS (nonmobile, older, rural, males). Ello quiere decir que la búsqueda de los fenómenos dialectales que reflejen arcaísmos y formas en desuso adquiere especial atención bajo la práctica de este tipo de dialectología.

Así, la metodología sobre la que se apoya el presente trabajo está estrechamente relacionada con las bases teóricas que enmarcan la geografía lingüística como método de la dialectología tradicional. No obstante, este atlas se desvía en algunos puntos metodológicos del modelo tradicional, como por ejemplo el uso exclusivo de los NORMS en la dialectología clásica. De allí que este sea un trabajo que se adapta 
teórica y metodológicamente a lo que Pilar García llamaría un "atlas cercano a los regionales con metodología modernizada" (García 2008, 12). Así, la ilustración de reliquias dialectales no es un objetivo en este atlas. Más bien, nuestro interés principal es presentar un estado actual y generalizado de la pronunciación del español en Belice a través de mapas.

La base metodológica se acerca mucho más al método propuesto por Harald Thun (1995, 1996) a partir de los resultados expuestos en el Atlas Dialectológico y Pluridimensional de Uruguay (ADDU), que luego sería adaptado parcialmente en el ALECORI (Quesada Pacheco 2010) y continúa como tal entre todos los proyectos que conforman el ALAC (Chavarría Úbeda \& Rosales Solís 2010). En pocas palabras, este es un método que incorpora variantes sociolingüísticas al método tradicional. De allí resulta su adjetivo 'pluridimensional', pues además de la dimensión diatópica se insertan también la variante diasexual y la diageneracional. Dichas variantes permiten mayor precisión al momento de interpretar los datos logrados.

En términos generales, lo que se ofrece con la aplicación de este método es facilitar la interpretación del entramado dialectológico inherente a toda lengua. Digamos que nuestro atlas cumple la misma función que cumple una fotografía satelital de un territorio cualquiera. Las imágenes obtenidas en el atlas lingüístico nos dan una idea del conjunto de elementos dialectales presentes en la zona. De dichos elementos, el dialectólogo tiene la posibilidad de identificar y ampliar las hipótesis, teorías y explicaciones que de tal observación se desprendan. En definitiva, el interés del lingüista es dar respuesta a lo que sucede en el campo de interacción lingüística. Sin dicha fotografía o imagen que proporciona el atlas lingüístico, el dialectólogo o lingüista queda a la deriva. Su monografía tendría como punto de partida otras anteriormente escritas, lo que puede incurrir en la perpetuación de sesgos cometidos previamente o en la falta de una perspectiva panorámica que pueda dar explicación a las particularidades del fenómeno que se estudia.

Es por ello que creemos que las disertaciones e hipótesis sobre la evolución de la lengua en cuestión encontrarán en el producto final de la geografía lingüística una herramienta de gran eficiencia, por su capacidad de condensar visualmente la complicada red de fenómenos lingüísticos en el campo de la interacción comunicativa humana real. El dialectólogo, al observar un atlas lingüístico, tiene la posibilidad de hacerse una idea general que le permite correlacionar lo que ve con lo que ya se conoce de la zona en cuestión. 


\section{Las localidades}

Si bien el español en Belice es hablado por más del 50\% del total de la población, la distribución geográfica de estos hablantes no es uniforme a lo largo y ancho del territorio beliceño. El parámetro de equidistancia relativa entre las localidades encuestadas que procura mantener el ALAC no puede mantenerse en este país. Las comunidades hispanohablantes en el país están limitadas a ciertas regiones. Normalmente, aquellas que han sido el lugar de asentamiento de los inmigrantes centroamericanos. No obstante, se trató de procurar una muestra de cada uno de los puntos en donde el español tiene participación importante en la vida diaria del beliceño.

Para la escogencia de las localidades tuvimos en cuenta que su población reflejara tanto la vida urbana como la rural. De allí que en cada distrito escogimos al menos una zona urbana y una zona rural.

Tabla 2. Localidades entrevistadas

\begin{tabular}{|c|c|}
\hline Distrito (de norte a sur) & Localidad \\
\hline \multirow[t]{2}{*}{ Corozal } & Corozal (zona urbana) \\
\hline & Progresso (zona rural) \\
\hline Ambergris Cay & $\begin{array}{l}\text { San Pedro (zona turística con presencia } \\
\text { de pescadores y agentes de turismo) }\end{array}$ \\
\hline \multirow[t]{2}{*}{ Orange Walk } & Orange Walk (zona urbana) \\
\hline & San Felipe (zona rural) \\
\hline \multirow[t]{3}{*}{ Cayo } & San Ignacio (zona urbana) \\
\hline & Soccutz (zona rural) \\
\hline & $\begin{array}{l}\text { Benque viejo del Carmen (zona } \\
\text { semiurbana) }\end{array}$ \\
\hline \multirow[t]{2}{*}{ Toledo } & Punta Gorda (zona urbana) \\
\hline & San Pedro Colombia (zona rural) \\
\hline
\end{tabular}




\section{El cuestionario y las entrevistas}

El cuestionario usado para Belice es básicamente el mismo que se ha venido usando para todos los proyectos abarcados por el ALAC el cual, a su vez, proviene del cuestionario que se usó para las entrevistas del ALECORI. La única diferencia radica en que nuestro cuestionario incluye cuatro preguntas adicionales con el fin de lograr mayor información relevante para el territorio entrevistado.

En total, es una lista de 61 incisos de preguntas indirectas y frases de completar dirigidas, que tienen como objetivo hacer que el entrevistado pronuncie cierta palabra en la cual se encuentra el contexto fonético que queremos registrar. La intención al usar la pregunta indirecta es que el entrevistador no pronuncie la palabra que queremos oír del informante y, de esta manera, disminuir la influencia articulatoria del primero sobre el segundo. Así, por ejemplo, para observar la pronunciación de la combinación / $\mathrm{rd} /$, en vez de preguntar “¿cómo dice usted morder?” preguntamos “complete la siguiente frase: perro que ladra no...". La respuesta más común suele ser muerde (ver Anexo).

Si bien el cuestionario se aplica en su totalidad a todos los entrevistados, es relevante mencionar que no hemos descartado algunas grabaciones de conversación libre, siempre que estas pertenecieran al mismo informante que ha respondido el cuestionario. Ello nos dio la oportunidad de comparar dichas conversaciones libres con los datos obtenidos del cuestionario y, así, determinar si se presentan casos de polifonía.

Las entrevistas fueron realizadas en un recorrido por el país que duró un mes y cinco días, realizada durante los meses de abril y mayo del año 2005. También se realizó otra visita, a mediados del 2006, con el fin de corregir y rellenar aquellos vacíos que, por diversas razones técnicas y de logística, se quedaron sin completar en la primera visita al país. En todos los casos las entrevistas fueron grabadas para ser posteriormente analizadas por el entrevistador y el director del proyecto ALAC, Miguel Ángel Quesada Pacheco.

En algunas ocasiones debimos recurrir a varios informantes en la misma localidad para completar un solo cuestionario. Ello porque algunas de las personas, sobre todo en las ciudades más grandes, tenían menos tiempo para responder el 
cuestionario completamente. No obstante, en todos los casos mantuvimos las condiciones que debían cumplir los informantes para ser relevantes en este estudio.

\section{Los informantes}

Siguiendo en lo posible los requisitos del ALAC para la escogencia de los informantes, en cada localidad se entrevistaron cuatro personas teniendo en cuenta su edad y su género. En el primer caso se diferenciaron dos grupos: jóvenes (mayores de 18 años que no sobrepasen los 35 años) y mayores (mayores de 60 años).

No obstante, en San Pedro Colombia, al sur de Belice y de descendencia kekchí, no se logró hallar un informante para el género femenino, mayor de 60 años, que, además, cumpliera con los requisitos estipulados por el proyecto: a) haber nacido en la localidad, de manera que su habla sea representativa de la variedad dialectal de la zona; b) tener padres oriundos de la zona; c) haber vivido en la zona la mayor parte de su vida y, preferiblemente, sin haber tenido largas ausencias (no más de cinco años); d) no tener impedimentos físicos que modifiquen la articulación normal de las palabras (buena dentadura, oído sano, sin enfermedades mentales que afecten el habla); e) no estar influidos fuertemente por instituciones académicas, pues estos informantes tienen una tendencia a modificar el habla con formas lingüísticas prescriptivas en contextos no familiares.

Al igual que en el caso de la escogencia de las localidades, en Belice, debieron hacerse algunas excepciones a la propuesta del 'informante ideal' definida para el ALAC. El requisito $b$ de tener padres oriundos de la zona no fue posible mantener en todos los casos. La realidad demográfica de Belice refleja una población hispanohablante mayoritariamente inmigrante. De ahí que aún hay zonas donde la población hispanohablante no va más allá de dos generaciones atrás, de manera que hallar a informantes mayores con padres oriundos de la zona fue uno de los problemas más comunes.

A continuación presentamos la tabla de informantes que señala, además de la edad y el género, sus profesiones u oficios y sus estudios. Esta última es información adicional valiosa, que aunque no fue sistemáticamente recogida, representa un buen punto de referencia para futuras disertaciones sobre la variación fonética del español en Belice. 
Tabla 3. Informantes entrevistados

\begin{tabular}{|c|c|c|c|c|c|}
\hline Informante & Edad & Sexo & Localidad & Ocupación & Estudios \\
\hline \multicolumn{6}{|c|}{ Corozal } \\
\hline Silvian Grey & 20 & M & Corozal & Estudiante & Técnicos incompletos \\
\hline Elena Castañeda & 28 & $\mathrm{~F}$ & Corozal & Bibliotecaria & Técnicos \\
\hline Arlan Guardia & 68 & M & Corozal & Pensionado & Primaria \\
\hline Nela Gonzáles & 60 & $\mathrm{~F}$ & Corozal & Comerciante & Secundarios \\
\hline Armin & 30 & M & Progresso & Profesor & Universitarios \\
\hline Angie & 21 & $\mathrm{~F}$ & Progresso & Ama de casa & Secundaria incompleta \\
\hline Amalio $\mathrm{Ke}$ & 83 & M & Progresso & Agricultor & \\
\hline Marina Wesley & 60 & $\mathrm{~F}$ & Progresso & Ama de casa & Primarios \\
\hline \multicolumn{6}{|c|}{ Amberguis Cay } \\
\hline Minelia & 18 & M & San Pedro & Estudiante & Secundaria incompleta \\
\hline Gonzalo Valdez & 60 & $\mathrm{~F}$ & San Pedro & Vendedor & Primarios \\
\hline César & 35 & M & San Pedro & Agente viajes & Técnicos \\
\hline $\begin{array}{l}\text { María } \quad \text { Elena } \\
\text { Lavailla }\end{array}$ & 65 & $\mathrm{~F}$ & San Pedro & Ama de casa & Secundaria incompleta \\
\hline \multicolumn{6}{|c|}{ Orange Walk } \\
\hline Aldo Muñi & 30 & M & Orange Walk & Peluquero & Técnicos \\
\hline Elodia Vallecín & 34 & $\mathrm{~F}$ & Orange Walk & Vendedora & Secundaria \\
\hline Marcelo Cocon & 71 & M & Orange Walk & Vigilante & Primaria \\
\hline Ofelia & 61 & $\mathrm{~F}$ & Orange Walk & Ama de casa & Primaria \\
\hline Valerio Magani & 21 & M & San Felipe & Peluquero & Secundaria \\
\hline Alina Magani & 19 & $\mathrm{~F}$ & San Felipe & Estudiante & Secundaria incompleta \\
\hline $\begin{array}{l}\text { Oswaldo } \\
\text { Dimínguez }\end{array}$ & 63 & M & San Felipe & Agricultor & Primarios \\
\hline
\end{tabular}




\begin{tabular}{|c|c|c|c|c|c|}
\hline Carmen Zetina & 61 & $\mathrm{~F}$ & San Felipe & Vendedora & Primarios \\
\hline \multicolumn{6}{|c|}{ Cayo } \\
\hline (Anónimo) & 28 & M & Benque Viejo & Granjero & \\
\hline (Anónimo) & 32 & $\mathrm{~F}$ & Benque Viejo & Bibliotecaria & \\
\hline Emilio Castellano & 75 & $\mathrm{M}$ & Benque Viejo & Terrateniente & Secundaria incompleta \\
\hline (Anónimo) & 18 & $\mathrm{~F}$ & Benque Viejo & Estudiante & Secundaria \\
\hline Emérito & 35 & M & Soccutz & Agricultor & Primaria \\
\hline Alicia & 35 & $\mathrm{~F}$ & Soccutz & Ama de casa & Secundaria incompleta \\
\hline Ermenegildo Pantí & 65 & $\mathrm{M}$ & Soccutz & Agricultor & Ninguno \\
\hline Engracia & 75 & $\mathrm{~F}$ & Soccutz & Ama de casa & Ninguno \\
\hline Orlando Flórez & 32 & M & San Ignacio & Comerciante & Secundaria \\
\hline Ereni Ascai & 21 & $\mathrm{~F}$ & San Ignacio & Estudiante & Secundaria incompleta \\
\hline Juan Zetina & 62 & $\mathrm{M}$ & San Ignacio & Vendedor & Secundaria incompleta \\
\hline Julia & 78 & $\mathrm{~F}$ & San Ignacio & Vendedora & Ninguno \\
\hline \multicolumn{6}{|c|}{ Toledo } \\
\hline Álvaro & 32 & M & Punta Gorda & Vendedor & Secundaria \\
\hline Claudia Crespo & 26 & $\mathrm{~F}$ & Punta Gorda & comerciante & Técnicos \\
\hline Pedro Zenteno & 61 & M & Punta Gorda & Mecánico & Primarios \\
\hline Otilia & 82 & $\mathrm{~F}$ & Punta Gorda & Ama de Casa & Primarios incompletos \\
\hline Oscar Reitena & 34 & M & $\begin{array}{ll}\text { San } & \text { Pedro } \\
\text { Colombia } & \\
\end{array}$ & Agricultor & Secundarios \\
\hline Nayomi Lara & 19 & $\mathrm{~F}$ & $\begin{array}{l}\text { San Pedro } \\
\text { Colombia }\end{array}$ & Vendedora & $\begin{array}{l}\text { Secundarios } \\
\text { incompletos }\end{array}$ \\
\hline Víctor & 80 & M & $\begin{array}{ll}\text { San } & \text { Pedro } \\
\text { Colombia } & \end{array}$ & Sin estudio & \\
\hline & ---- & ---- & $\begin{array}{ll}\text { San } & \text { Pedro } \\
\text { Colombia } & \end{array}$ & -------- & 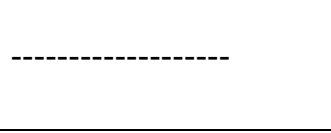 \\
\hline
\end{tabular}




\section{Los mapas}

Se trata de una serie de 61 mapas pluridimensionales de tipo intermedio sintéticoanalítico. Es decir, cada mapa representa los 61 contextos fonéticos que hemos registrado durante el trabajo de campo. Este tipo de mapas no tiene la respuesta de cada informante en cada uno de los puntos, como suele suceder en los mapas analíticos puntuales, sino que tales respuestas estarán representadas por un cuadrante coloreado al lado del nombre de la localidad. Ya que entrevistamos cuatro informantes por localidad discriminados según sexo y edad, cada mapa ilustrará un cuadro dividido en cuatro cuadrículas para representar a cada informante en cada punto de la red así:

\begin{tabular}{|l|l|}
\hline HМ & MM \\
\hline HJ & MJ \\
\hline
\end{tabular}

HM: persona del sexo masculino, mayor de 60 años

MM: persona del sexo femenino, mayor de 60 años

HJ: persona del sexo masculino, entre 18 y 36 años

MJ: persona del sexo femenino, entre 18 y 36 años

Cada cuadrícula especificará un contexto fonético mediante un color que estará listado a manera de convención, al lado del mapa, señalando, así, la articulación fonética para cada informante. Además, como anexo, hemos incluido los seis mapas que resultan de cada uno de los mapas que presentaremos en el análisis: uno según el género; uno según la edad y cuatro para cada informante.

Cada uno de los mapas incluidos en el análisis irá acompañado, como parte del análisis, por dos tablas. Una ilustrará el porcentaje de realización según la muestra general, sin discriminación generacional o sexual, para cada uno de los fenómenos que se ilustran en los mapas. La segunda tabla ilustrará los porcentajes según el sexo y según la edad de los informantes. 


\section{Bibliografía}

Alvar, M. \& A. Quilis. 1984. Atlas lingüístico de Hispanoamérica. Cuestionario. Estudios introductorios de Manuel Alvar. Madrid: Instituto de Cooperación Iberoamericana.

Chambers, J. K. \& P. Trudgill. 1994. La Dialectología. Traducción al español de Carmen Morán González. Madrid: Visor. Título original: Dialectology. Cambridge University Press.

Chavarría Úbeda, C. \& M. A. Rosales Solís. 2010. Atlas lingüistico etnográfico de Nicaragua (ALEN). Managua: PAVSA.

Coseriu, E. 1985. El hombre y su lenguaje. Madrid: Editorial Gredos.

Crystal, D. 2003. A dictionary of linguistics and phonetics. Fifth edition. Oxford: Blackwell Publishing.

Escure, G. J. 2004. Creoles, Contact and Language Change: Linguistics and social implications. Philadelphia: John Benjamins Publishing Company. 34-65.

García Mouton, P. 1996. Dialectología y geografía lingüística. Manual de dialectología hispánica. El español de España. Manuel Alvar (ed.): 63-77. Barcelona: Ariel. 2008. Los Atlas lingüísticos y el español de América. Donde dice. Boletín de la fundación del español urgente. Vol. 10. Madrid: Fundación del español urgenteFundéu BBVA. Consultado en http://www.fundeu.es/IMAGENES/revistaPDF/633366957095468750.pdf

Gimeno Menéndez, F. 1990. Dialectología y sociolingüístca españolas. Alicante: Universidad de Alicante.

Iordan, I. 1970. An Introduction to Romance Linguistics. Its Schools and Scholars. Oxford: Basil Blackwell.

Milroy, L. \& M. Gordon. 2003. Sociolinguistics. Method and Interpretation. Oxford: Blackwell Publishing.

Montes Giraldo, J. J. 1970. Dialectología y geografia lingüistica. Notas de orientación. Bogotá: Instituto Caro y Cuervo.

Munteanu Colán, D. 2005. Breve historia de la lingüística románica. Madrid: Arco Libros.

Quesada Pacheco, M. Á. (coord.). 2010. Atlas lingüístico-etnográfico de Costa Rica (ALECORI). San José: Editorial de la Universidad de Costa Rica. 
Shoman, A. 1994. Chapters of a History of Belize. Belize City: The Angelus Press Ltd.

Thun, H. 1995. La pluridimensionalidad en el Atlas Lingüístico Diatópico y Diastrático del Uruguay (ADDU). Cartografía de un atlas pluridimensional. I Congreso del Español de América [Burgos, 5-11 de noviembre de 1995]: 12791311.

1996. Movilidad demográfica y dimensión topodinámica. Los montevideanos en Rivera. Dialectologia Pluridimensionalis Romanica. Akten des symposiums zur empirischen dialektologie. Westensee - Verlag Kiel: 210-269.

Verbeeck, L. 1999. Linguistic Acculturation in Mopan Maya. A study of language change in Belizean Mopan due to Spanish and English culture and Language Contact. Lincom Studies in Native American Linguistics 05. München: Lincom Europa.

\section{Otras fuentes}

Censo de 2010 en Belice:

http://www.statisticsbelize.org.bz/dms20uc/dynamicdata/docs/ 20110505004542 2.pdf.

Segundo informe sobre desarrollo humano en Centroamérica y Panamá. Capítulo 8 http://www.estadonacion.or.cr/index.php/bibliotecavirtual/centroamerica/aspectos-sociales/aspectos-anteriores/informe-ii-cap-8. 


\section{Anexo I \\ ATLAS LINGÜÍSTICO ETNOGRÁFICO (PLURIDIMENSIONAL) \\ DE PANAMÁ y BELICE. \\ CUESTIONARIO FONÉTICO}

\section{Vocales postónicas finales}

$1-$ a: cuando uno no está en calle uno está en (casa)

2 -e: después de diez sigue (once)

$3-0$ : el animal que dice miau es el (gato)

4 -as: un animal camina con las (patas)

5 -es: uno mastica con los (dientes)

6 -os: las gallinas ponen (huevos)

7 -sas: las mujeres de los esposos son las (esposas)

Tienen alas de colores y van de flor en flor (mariposas)

\section{Consonantes}

8 b tras ai: como se llama el cangrejo pequeño de mar (jaiba)

El árbol en el que lloraba la Llorona (el Ceibo / la Ceiba)

Lo contrario de muy malo es (muy bueno)

9 b tras l: la tierra fina que se levanta en el aire se llama (polvo)

Alguien que no tiene pelo también se le dice (calvo)

10 b tras r: el camino que no es recto tiene muchas (curvas)

Mostrar una foto de un árbol o señalarlo

Al juez de un partido de fútbol se le llama (árbitro)

A un complejo de viviendas o condominio ¿también se le dice? (urbanización)

$11 \mathrm{~d}$ tras eu: el que pide dinero prestado tiene muchas (deudas)

$12 \mathrm{~d}$ tras 1: la parte líquida de la sopa se llama (caldo). Al jugo de la caña también se le llama (caldo)

Lo que se usa en puertas o ventanas para poner seguro (aldaba, aldabilla)

También se le puede señalar, si la hay en la casa, o mostrarle una foto.

$13 \mathrm{~d}$ tras r: muchos perros ladran, pero no (muerden)

Si molestas un perro te puede (morder) 
Cuando te quemas por el sol sientes un (ardor)

$14 \mathrm{~d}$ en -ado: después de trabajar mucho uno está (cansado)

15 g tras ui: ¿de qué otra manera se puede decir "yo escucho"? (oigo)

¿Lo contrario de muy pequeño? (muy grande)

$16 \mathrm{~g}$ tras 1: el animalito que hace que el perro se rasque la piel se llama (pulga)

Las plantas verdes que flotan en la orilla del mar se llaman (algas)

$17 \mathrm{~g}$ tras r: (con dos palitos) si este palito es corto el otro es (largo)

Las espinacas o el café sin azúcar tienen un sabor (amargo)

$18 \mathrm{f}$ ante a: padre madre e hijos hacen una (familia) (se puede usar foto)

19 f ante e: lo que se bebe por la mañana es (café)

20 f ante o: con una cámara se toman (fotos)

21 f ante i: un cuchillo que no corta bien no tiene (filo)

Cuando terminas algo es porque has llegado al (final)

El último partido del torneo es la (final)

22 f ante u: el deporte que más se ve en la tele es (fútbol)

Si ayer fue pasado, hoy es presente, mañana será (futuro)

23 f ante ie: una persona que tiene fidelidad se dice que es (fiel)

Cuando hay algo que celebrar se hace una (fiesta)

24 f ante ue: una persona que puede levantar mucho peso es una persona (fuerte)

¿Cómo se le llama también a la pileta de agua que está en el parque? (fuente)

(se puede usar foto)

25 f ante l: una rosa es una (flor) (se puede usar foto)

26 s inicial: la estrella que nos da vida y luz en la tierra es el (sol)

27 s intervocálica: la flor de los enamorados es la (rosa) (se puede usar foto)

28 s final: para ver se usan (los ojos / anteojos / lentes $)$

29 s final y ante t: el país más rico de América es (Estados Unidos ) (usar bandera)

30 s ante p: la escamilla blanca del pelo se llama (caspa)

La pastillita que se toma para el dolor de cabeza se llama (aspirina)

El fantasmita amistoso se llama (Gasparín)

31 s ante k: cómo se le llama a la comida de mar (mariscos / pescado)

Un perro furioso le puede pegar a uno un (mordisco)

$32 \mathrm{~s}$ ante b: la sangre corre por (las venas)

33 s ante d: para saludar en la mañana uno dice (buenos días)

34 s ante g: los ratones le tienen miedo a (los gatos) 
Si tengo muchos ratones en este lado y muchos gatos en este otro, al dejarlos libres lo normal es que los ratones le corran a (los gatos). (Asegurarse de que lo diga con el artículo y en plural).

$35 \mathrm{~s}$ ante $\mathrm{m}$ : alguien que no puede respirar bien posiblemente sufre de (asma)

¿De qué otra manera se le dice a un temblor de tierra? (sismo)

$36 \mathrm{~s}$ ante $\mathrm{n}$ : para saludar por las noches se dice (buenas noches)

37 s ante vibrante: uno se hinca con (las rodillas). Señalar la parte y asegurarse que lo dice usando el artículo.

38 s ante 1: un terreno rodeado de agua se llama (isla)

$39 \mathrm{~h}$ ante a: uno se lava con (jabón)

40 h ante o: el padre de Jesús de Nazareth se llama (José)

Una cadena de oro o un anillo, o un brazalete es una (joya)

$41 \mathrm{~h}$ ante $\mathrm{u}$ : después de mayo sigue (junio)

$42 \mathrm{~h}$ ante e: cuando hay conciertos o presentaciones públicas se reúne mucha (gente)

El lugar en el hospital al que llegas cuando estás gravemente herido se llama (urgencias)

$43 \mathrm{~h}$ ante i: una caja pequeña es una (cajita). Si el diminutivo de máquina es maquinita, el diminutivo de caja es (cajita)

44 ch: después de siete sigue (ocho)

45 n posnuclear y final: lo que uno canta se llama (canción

46 r final: la cocina sirve para (cocinar)

Los ojos sirven para (ver)

47 rr inicial: el color de la sangre es (rojo)

Los gatos persiguen a los (ratones)

Alguien que no hace caso de nada es un (rebelde)

48 rr intervocálica: el animal que dice guau guau es el (perro)

Al cerdo también se le dice (marrano)

49 r ante k: para comprar comida hay que ir al (mercado)

Para lanzar flechas ¿se necesita un? (arco)

$50 \mathrm{r}$ ante $\mathrm{n}$ : después del jueves sigue (viernes)

$51 \mathrm{r}$ ante m: las mujeres de blanco que ayudan a los médicos se llaman (enfermeras)

Los cuchillos, las pistolas, los fusiles, las bombas, etc. son... (armas)

$52 \mathrm{r}$ ante 1: la piedra preciosa que es una bola muy pequeña y muy blanca se llama (perla) 
¿Cómo se llama el príncipe de Inglaterra? (Carlos)

$53 \mathrm{r}$ ante s: los presos están en la (cárcel)

54 y inicial: la hembra del caballo es la (yegua)

El agua que cae del cielo es la (lluvia)

55 y intervocálica: ¿de qué color es el sol? (amarillo) (brillante)

56 y tras n: la aguja con líquido de la enfermera se llama (inyección)

Cuando te vacunan utilizan una (inyección)

57 tr inicial e intervocálico: después de dos siguen (tres, cuatro)

58 str: la persona que enseña en la escuela se llama (maestra)

El que estudia las estrellas es un (astrónomo)

Quitarle las pelotas a un novillo se llama (castrar)

59 ndr: las aves negras con blanco, pequeñas, que llegan por montones, generalmente cuando va a cambiar el tiempo son las (golondrinas). Una.... no hace verano.

60 nr: si le doy vueltas y vueltas a este cable ¿me queda? (enredado / enrollado)

61 ldr: ¿cuál sería el futuro de él sale? (saldrá)

Hecho de harina con consistencia crocante y azúcar por encima (hojaldre) 